\title{
Spirituality and Health Services in Iran
}

\author{
Nadereh Memaryan ${ }^{1}$ and Shahrbanoo Ghahhari ${ }^{2,3, *}$ \\ ${ }^{1}$ Spiritual Health Research Center, Iran University of Medical Sciences, Tehran, Iran \\ ${ }^{2}$ Department of Mental Health, Center of Excellence in Psychiatry, School of Behavioral Sciences and Mental Health, Iran University of Medical Sciences, Tehran, Iran \\ ${ }^{3}$ Psychiatry and Behavioral Sciences Research Center, Addiction Institute, Mazandaran University of Medical Sciences, Sari, Iran \\ "Corresponding author: Assistant Professor of Clinical Psychology, Department of Mental Health, Center of Excellence in Psychiatry, School of Behavioral Sciences and Mental \\ Health, Iran University of Medical Sciences, Tehran, Iran. Tel: +98-2163471299, Fax: +98-2166506853, Email: ghahhari.sh@iums.ac.ir
}

Received 2017 May 03; Revised 2017 August 28; Accepted 2017 December 01.

Keywords: Health Services, Iran, Spirituality

\section{Dear Editor,}

There have long been debates over spiritual health with so many studies conducted and so many papers published (1). Iran is one of the top six countries active in publishing papers related to spirituality and health in the world (2). Despite all these studies, the following questions arise: Is the concept reflected in the provision of essential health care? To what extent are the services provided to the people influenced by their spiritual health? Is the spiritual history taking similar to the history taking of any other problems that is normally conducted? How many local protocols and guidelines are available for spiritual treatment and interventions? The efforts of some countries to advance these points are observed in the published scientific documents (3).

We define spirituality as a dimension of the human being that guides him towards his transcendence, which is closeness to Allah. The purposefulness of life, bearing difficulties in life, establishing relationships with the creator, the universe, and other creatures in this universe are the consequences of developing this dimension of human existence. What is remarkable is the peace and life satisfaction, which emerges pursuant to promoting and respecting spirituality in people's lives (4). Spirituality helps people in coping with stress and illness. It even affects their behavior towards events due to the disease and even their adherence to the treatment (5).

When considering that such a concept has so many effects, why it has no place in our health services? One reason could be the lack of training in this regard (6). Of course, training on such abstract and sensitive issues that depend on the culture and belief contexts needs its own specific texts and resources. In addition to providing texts, because of the centrality of academic educations in Iran that re- quires the texts and educational programs to be verified and then communicated from the concerned ministries, a serious determination and persistence are also essential to promote suitable areas to provide the spiritual services in health care centers (7). The strategic document for Iran health system by 2025 has drawn the policy towards the spiritual health (8) and there is hope for the integration of spiritual services with the health system and fulfillment of the conditions needed for its implementation in the coming years.

Hence, although many necessary conditions for the integration of spiritual services with the common services of health are not provided, sensitizing health providers and providing very simple training in the field of spirituality and health, whose documentation is frequent, by committed and caring researchers and professionals in the field will lead to addressing this neglected but important dimension.

\section{Footnotes}

Authors' Contribution: Nadereh Memaryan conceptualized the study. Shahrbanoo Ghahhari administrated the submission.

Declaration of Interest: None declared.

Funding/Support: None.

\section{References}

1. Jafari N, Loghmani A, Puchalski CM. Spirituality and health care in Iran: Time to reconsider. J Relig Health. 2014;53(6):1918-22. doi: 10.1007/s10943-014-9887-2. [PubMed: 24912827].

2. Lucchetti G, Lucchetti AL. Spirituality, religion, and health: Over the last 15 years of field research (1999-2013). Int J Psychiatry Med. 2014;48(3):199-215. doi: 10.2190/PM.48.3.e. [PubMed: 25492714]. 
3. Puchalski CM, Blatt B, Kogan M, Butler A. Spirituality and health: The development of a field. Acad Med. 2014;89(1):10-6. doi: 10.1097/ACM.0000000000000083. [PubMed: 24280839].

4. Memaryan N, Rassouli M, Mehrabi M. Spirituality concept by health professionals in Iran: A qualitative study. Evid Based Complement Alternat Med. 2016;2016:8913870. doi: 10.1155/2016/8913870. [PubMed: 27493675]. [PubMed Central: PMC4967431].

5. Bussing A, Baumann K, Hvidt NC, Koenig HG, Puchalski CM, Swinton J. Spirituality and health. Evid Based Complement Alternat Med. 2014;2014:682817. doi: 10.1155/2014/682817. [PubMed: 24616739]. [PubMed Central: PMC3926235]

6. Memaryan N, Rassouli M, Nahardani SZ, Amiri P. Integration of spiri- tuality in medical education in Iran: A qualitative exploration of requirements. Evid Based Complement Alternat Med. 2015;2015:793085. doi: 10.1155/2015/793085. [PubMed: 26688688]. [PubMed Central: PMC4672123].

7. Memaryan N, Jolfaei AG, Ghaempanah Z, Shirvani A, Vand HD, Ghahari $S$, et al. Spiritual care for cancer patients in Iran. Asian PacJ Cancer Prev. 2016;17(9):4289-94. [PubMed: 27797232].

8. Rostamigooran N, Esmailzadeh H, Rajabi F, Majdzadeh R, Larijani $\mathrm{B}$, Dastgerdi MV. Health system vision of Iran in 2025. Iran J Public Health. 2013;42(Supple1):18-22. [PubMed: 23865011]. [PubMed Central: PMC3712583]. 